\title{
Threshold-dependent climate effects and high mortality limit recruitment and recovery of the Kattegat cod
}

\author{
Martin Lindegren ${ }^{1,2, *}$, Margit Eero ${ }^{2}$ \\ ${ }^{1}$ Scripps Institution of Oceanography, University of California, 9500 Gilman Drive, La Jolla, California 92093-0218, USA \\ ${ }^{2}$ National Institute of Aquatic Resources, Technical University of Denmark, Charlottenlund Castle, Charlottenlund 2920, \\ Denmark
}

\begin{abstract}
Cod in the Kattegat is one of the most dramatic examples of stock collapse, where despite large management efforts, almost no signs of recovery have been observed. We investigate how multiple physical and biological factors could potentially influence recruitment and recovery of Kattegat cod, using non-additive threshold models. In contrast to previous studies on recruitment dynamics of Kattegat cod Gadus morhua, we found that recruitment variability may be explained by a combination of the size of the spawning stock and external conditions (i.e. sea surface temperature and oxygen concentrations), but only during periods of low stock size. Our results indicate that the long-term decrease and the present poor state of the Kattegat cod stock is likely caused by high total mortality rates and stock-size dependent effects of climate which together are currently preventing recovery. In addition, we illustrate how only a drastic reduction in total mortalities, primarily by limiting unintended bycatch and discards, may promote a recovery of the stock. This knowledge is important for evaluating the success or failure of various management measures which have been employed to recover the stock and for developing future management strategies which can take the environmental and/or ecosystem impacts into account.
\end{abstract}

KEY WORDS: Recovery $\cdot$ Climate $\cdot$ Thresholds $\cdot$ Recruitment $\cdot$ Cod $\cdot$ Management $\cdot$ Kattegat · Modelling

Resale or republication not permitted without written consent of the publisher

\section{INTRODUCTION}

Despite large management efforts at regional and local scales to enhance and stimulate population growth, several cod Gadus morhua stocks throughout the North Atlantic remain severely depleted (Hutchings \& Reynolds 2004, Lilly et al. 2008, Hutchings et al. 2010), with only a few stocks showing signs of recovery, e.g. the Eastern Baltic cod (Eero et al. 2012). This could be due to (1) persistent overexploitation (Shelton et al. 2006), (2) unfavourable environmental conditions (Beaugrand et al. 2003, Köster et al. 2005), (3) eradication of spawning components
(Svedäng et al. 2010, Lindegren et al. 2013), (4) an allee effect at low population size (Courchamp et al. 2009, Keith \& Hutchings 2012), (5) trophic interactions, preventing recovery through negative feedbacks on ecosystem structure and functioning (Frank et al. 2005, Llope et al. 2011), or a combination of all the above. Related mechanisms and interactions, and consequently the reasons for a lack of recovery of many cod stocks, are generally not well understood (Hilborn \& Litzinger 2009). However, understanding the causes of declining and continuously low stock levels is essential for developing and implementing effective management strategies to facilitate recov- 
ery of these commercially and ecologically important marine resources (Lindegren et al. 2009, McLeod \& Leslie 2009).

Stock recovery has generally been found to be more likely to occur during positive recruitment events related to favourable productivity regimes (Caddy \& Agnew 2004, Wakeford et al. 2009, Hammer et al. 2010). Recruitment of cod populations is usually a function of the size of the spawning stock, and has additionally been related to a suite of different physical and biological processes, mainly associated with the effects of temperature, salinity, oxygen, turbulence, advection, as well as food availability for early life stages (Ottersen et al. 2001). For example, cod recruitment in the North Sea has been explained by biotic factors related to match-mismatch in the timing and relative abundance of key prey species for larvae (Beaugrand et al. 2003), while in the neighbouring Baltic Sea, abiotic factors related to salinity and oxygen conditions have been shown to affect recruitment success through egg and larval mortality (Köster et al. 2005, Margonski et al. 2010). Furthermore, cod recruitment is strongly affected by climate forcing, primarily during periods of low stock size (Brander 2005), likely due to increased sensitivity caused by fishing-induced demographic changes (Ottersen et al. 2006, Anderson et al. 2008).

Cod in the Kattegat, a transition area between the Baltic and the North Sea, represents one of the most dramatic examples of reduction of a once-productive local cod population. The average recruitment of Kattegat cod is at present $<10 \%$ of the level in the early 1970s, and the spawning stock biomass (SSB) has subsequently fallen to $<5 \%$ of the historical stock size (ICES 2012). This drastic decline of the Kattegat cod stock has mainly been ascribed to the effect of intensive exploitation, whereas no significant ecosystem or environmental effects (e.g. temperature, salinity and oxygen) have hitherto been found (Cardinale \& Svedäng 2004). A large number of management efforts have been implemented in recent years to promote a recovery of the stock; these include development of a recovery plan (EC 2008), drastic reduction in landing quotas, various gear restrictions, closed areas and seasons (ICES 2012) and intensified fisheries control. Despite these efforts, the stock has shown almost no signs of recovery (Fig. 1).

In the present paper, we investigate how multiple abiotic and biotic factors and their synergistic effects could potentially influence cod recruitment and recovery in the Kattegat. Using non-additive threshold models and a data set of abiotic and biotic variables, we explore whether threshold-dependent external (climate-mediated) processes could explain some of the variability and long-term trends in Kattegat cod recruitment, in addition to the size of the spawning stock. In particular, we investigate whether cod recruitment is more sensitive to climate forcing during periods of low stock size, as suggested by Brander (2005). Furthermore, we discuss the limits to cod recovery under different climate and mortality scenarios, arguing that only a drastic reduction in total mortalities may promote a recovery and sustainable exploitation of the stock.

\section{MATERIALS AND METHODS}

\section{Ecosystem characteristics}

The Kattegat is commonly regarded as a transition area between the North and Baltic Seas, both in terms of abiotic (i.e. hydrography and nutrients) and biotic conditions (Andersson 1996). It is generally shallow with an extensive shelf ( 10 m depth) covering most of the western part, although a deeper trench $(>90 \mathrm{~m})$ runs along the Swedish coast in the eastern part of the area. Hydrographic conditions are highly variable and largely influenced by wind patterns, river run-off, sea-level variations and atmospheric pressure (Danielsson et al. 2004). The hydrodynamic regime is dominated by the southward flow of highly saline bottom water from the North Sea and the Baltic surface current transporting brackish water northward (Pedersen 1993). This results in a strong northwest-southeast salinity gradient and pronounced stratification (Gustafsson 2000). The Kattegat has experienced severe problems with eutrophication, hypoxia and seasonal fish kills (Conley et al. 2007). However, nitrogen and phosphorus levels have shown a decreasing trend since the mid-1980s (Rydberg et al. 2006), causing a decline in primary productivity, key phytoplankton and zooplankton groups (Henriksen 2009) and associated alterations in higher trophic levels (Lindegren et al. 2012).

\section{Data collection}

To investigate potential direct and indirect effects of abiotic and biotic processes on cod recruitment in the Kattegat, we selected a number of variables characterising the regional ocean-atmospheric forcing as well as local hydrographic conditions. Selection of variables as potential predictors for cod recruitment in the Kattegat was based on previous knowledge of 

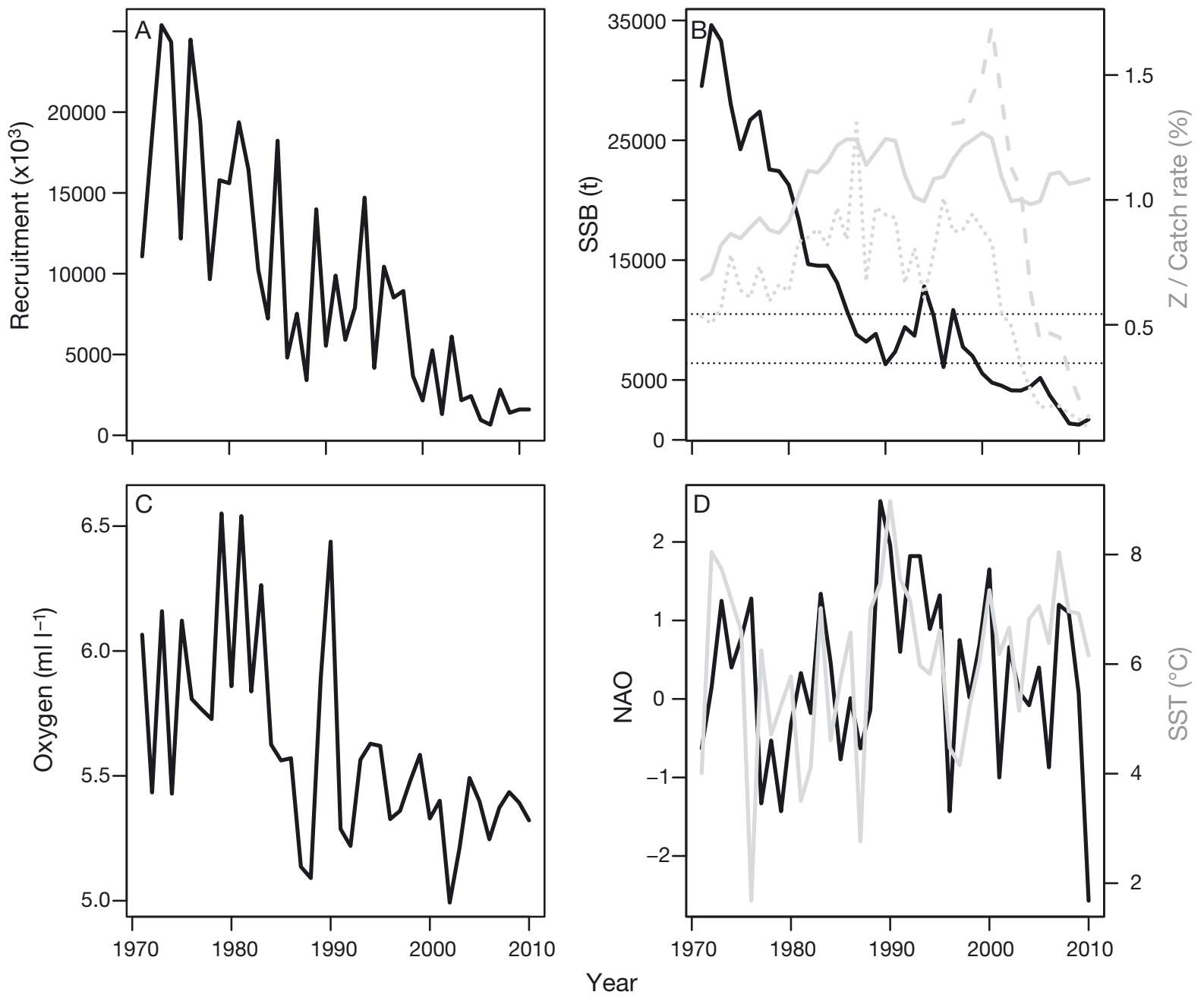

Fig. 1. Long-term trends in (A) cod Gadus morhua recruitment and (B) spawning stock biomass (SSB, black), mean total mortalities at Ages 3 to $5\left(\mathrm{Z}_{3-5}\right)$ based on 2 assessment runs, i.e. estimating total removals within the model (solid grey line) or explicitly including discards (dashed grey line), and catch ratios (landings:SSB; dotted grey line). Horizontal dotted lines represent the precautionary and limiting stock sizes $\left(B_{\mathrm{pa}}\right.$ and $\left.B_{\mathrm{lim}}\right)$. Atmospheric and hydrographic conditions are illustrated by

(C) mean annual bottom oxygen concentrations and (D) the NAO (black) and spring sea surface temperature (SST, gray)

recruitment processes in the entire distribution range of Atlantic cod, the length of the time series and the completeness of the dataset. To reflect the oceanatmospheric conditions affecting regional climate in the area, the North Atlantic Oscillation Index (NAO) was used. Physical conditions were represented by spring averages (March to May) of sea surface temperature (SST) and salinity (at 40 to $80 \mathrm{~m}$ ) during the extended period covering spawning as well as the pelagic egg and larval stages (Vitale et al. 2005). To account for the effect of oxygen conditions impacting recruitment throughout the early-life history, particularly seasonally occurring hypoxia and anoxia (Conley et al. 2007), we used the mean annual bottom oxygen concentrations. Finally, a survey-based index of recruitment at Age 1 (during the 1st quarter) from the neighbouring Skagerrak $\left(\mathrm{R}_{\mathrm{SR}}\right)$ was included due to the potential drift and migration of larvae and juveniles into the area (Cardinale \& Svedäng 2004). All abiotic and biotic data were extracted from published reports and the databases hosted by the Swedish Meteorological Institute (www.smhi.se) and the International Council for the Exploration of the Sea (ICES) (www.ices.dk). Recruitment (R), SSB and total mortality (Z) values of Kattegat cod originated from the most recent stock assessment (ICES 2012).

The present level of fishing mortality $(\mathrm{F})$ for cod in the Kattegat is unknown due to a pronounced difference between the catch data (landings plus discards) and the total removals from the stock estimated 
within the model based on survey data (ICES 2012). At present, the relative proportion of unallocated removals due to fishing (e.g. unaccounted discards) and biology-driven factors (e.g. migration or stock mixing issues with neighbouring stocks, such as the North Sea) cannot be specified. Therefore, ICES formally presents 2 assessment runs for this stock: (1) excluding discard information and estimating total removals within the model based on survey information and (2) using landings and discard data as total removals from the stock in excess of assumed natural mortality $(\mathrm{M}=0.2)$. The latter approach results in lower estimated total mortality rates compared to the first approach, which excludes discard information (Fig. 1B). These uncertainties have relatively little influence on SSB and long-term trends in recruitment but are highly influential on the estimates of mortality (ICES 2012). In our analyses, we used R and SSB values from the first assessment run covering the entire time period from 1971 to 2011, while total mortalities by age from both runs were used during simulations.

\section{Statistical analysis and stock-recruitment modelling}

To account for potential threshold-dependent relationships on recruitment, we used a modified formulation of generalized additive models, the so-called threshold generalized additive model (TGAM), allowing for non-additive effects of the explanatory variables below and above a certain threshold value (Ф) estimated from the data (Ciannelli et al. 2004). Since our aim was to investigate whether potential climate effects are dependent on stock size (Brander 2005), we defined SSB as the threshold variable and allowed the model to test for potential threshold values. The following non-additive model formulation with log-transformed recruitment ( $R$ at Age 1$)$ as the response variable was used:

$\ln \left(\mathrm{R}_{t+1}\right)=a+\left\{\begin{array}{l}\mathrm{s}\left(\mathrm{SSB}_{t}\right)+\mathrm{s}\left(\mathrm{V}_{1, t}\right)+\ldots+\mathrm{s}\left(\mathrm{V}_{\mathrm{n}}, t\right)+\varepsilon_{t} \text { if } \mathrm{SSB}>\Phi \\ \mathrm{s}\left(\mathrm{SSB}_{t}\right)+\mathrm{s}\left(\mathrm{V}_{1, t}\right)+\ldots+\mathrm{s}\left(\mathrm{V}_{\mathrm{n}, t}\right)+\varepsilon_{t} \text { if } \mathrm{SSB} \leq \Phi\end{array}\right.$

where $a$ is the intercept, $\mathrm{s}$ is the thin plate smoothing function (Wood 2003), SSB is the spawning stock biomass, $V_{1} \ldots V_{n}$ is a number of selected predictors potentially affecting cod recruitment, $\varepsilon$ is the error term, and $t$ is time (in years). We applied a stepwise backward selection routine based on the generalized cross validation criterion (GCV) (Wood 2004) and partial F-tests to find the best possible set of predictors. Furthermore, the degrees of freedom of the spline smoother function (s) were constrained to 3 knots $(k=3)$ to allow for potential nonlinearities but restrict flexibility during fitting. Finally, we tested whether the final non-additive model proved significantly better than a regular GAM (fitted without thresholds) by comparing the genuine $\mathrm{CV}$, i.e. the average squared leave-one-out prediction errors (Ciannelli et al. 2004).

\section{Model validation and future scenarios}

To validate the predictive capabilities of the recruitment model, we hindcasted the historical recruitment levels using a standard age-structured cohort model (i.e. age classes 1 to $6+$ ). The model was initialised with the estimated numbers-at-age in 1971 (ICES 2012) and run throughout the period with observed climate predictors and $\mathrm{Z}$ at age from the stock assessment run, estimating total removals within the model. To account for uncertainty, we added process noise to the recruitment estimates at each time step, i.e. resampled from the residuals of the final stock-recruitment model, and performed 1000 replicated model runs. The hindcasted recruitment estimates were then compared with the actual observed values of cod recruitment to validate the predictive accuracy of the model. As a preliminary assessment of the limits to cod recovery, we simulated the cod stock dynamics over a $10 \mathrm{yr}$ period under different climate and mortality scenarios. Hence, the age-structured model was initialised with the most recent estimates of numbers-at-age in 2011 and projected forward given age-specific $Z$ from the 2 assessment runs produced in ICES (2012), ranging from 0.2 to 1.2 .

To reflect the impact of favourable and unfavourable climate conditions on recruitment and stock recovery, the final climate predictors were maintained at levels resembling the observed maximum and minimum levels as well as the mean, 1st and 3rd quantile of their historical distribution. Finally, we performed 1000 stochastic runs (i.e. with added process noise resampled from the residuals of the stockrecruitment model) and calculated the probability of stock recovery, defined as the percentage of simulations in which the SSB increased above the estimated threshold level based on the TGAM (i.e. 7193 t, see Table 2) and the currently recommended precautionary stock size $\left(B_{\mathrm{pa}}=10500 \mathrm{t}\right)$, for each combination of mortality and climate. All statistical analyses were conducted using the R software version 2.5.1 (www. r-project.org). 
Table 1. Backward model selection. The generalized cross-validation criteria (GCV), total deviance explained (DEV; \%) and the significance of the partial F-test (p) are shown. The symbols $>$ and $<=$ denote the effects of each predictor above and less than or equal to the threshold value $(\Phi)$ estimated during model fitting. The final model is indicated in bold. SSB: spawning stock biomass; T: temperature; SAL: salinity; O2: oxygen; R: recruitment; $\mathrm{R}_{\mathrm{SR}}$ : Skagerrak cod recruitment index. Note that the NAO was excluded during model selection due to collinearity with sea surface temperature (e.g. Fig. 1D)

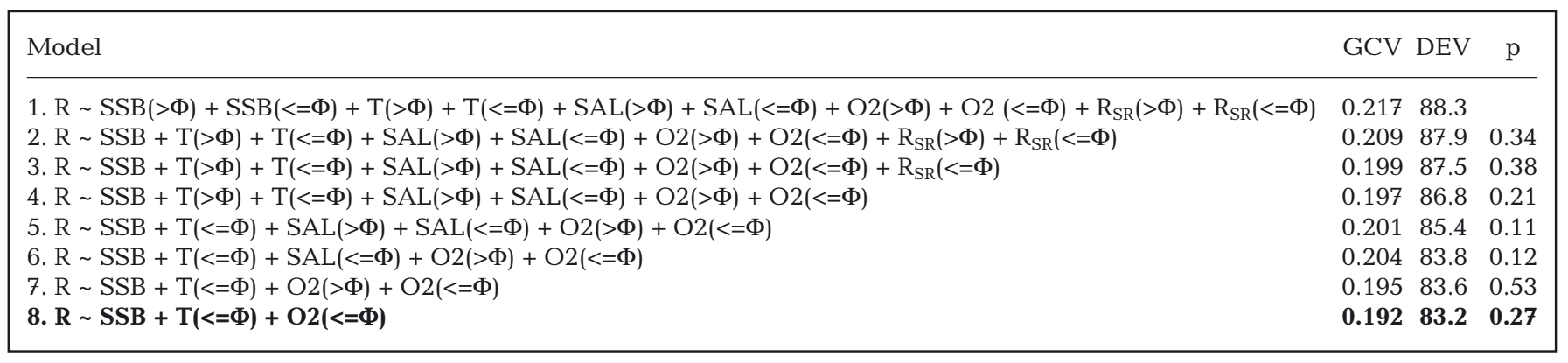

\section{RESULTS}

Backward model selection retained only cod SSB, spring SST and annual mean oxygen concentrations in the final model (Tables $1 \& 2$ ). The final relationship between recruitment and SSB was represented by a non-linear increasing function across the entire range of SSB (Fig. 2A), indicating potential density dependence at high stock levels. The functional relationship with spring SST and bottom oxygen showed a linear decreasing and increasing relationship, respectively (Fig. 2B,C). However, note that the climate effects were significant only at low stock sizes, below an estimated threshold level of $7193 \mathrm{t}$ (Fig. 2D). The final model explains well the longterm dynamics and a decline of cod recruitment in the Kattegat ( $83.2 \%$ of the total deviance explained) but demonstrates larger inter-annual variability during the last decade (Fig. 2E) due to climate influence once SSB drops below the estimated threshold. Nevertheless, observed recruitment levels are within the

Table 2. Final model parameters and intercept, smooth terms, estimated spawning stock biomass (SSB) threshold $(\Phi$; tonnes) and total deviance explained (DEV). Results from a sensitivity analysis when fitting the model without a (possibly) influential observation at high oxygen levels (Fig. 2C) are shown within parentheses. edf: estimated degrees of freedom for the model smoothing terms, where edf $>1$ indicates a non-linear relationship. SST: sea surface temperature

\begin{tabular}{|lccc|}
\hline Intercept & p-value & Threshold $(\Phi)$ & DEV (\%) \\
\hline $9.10(9.09)$ & $<0.001(<0.001)$ & $7193(7164)$ & $83.2(83.4)$ \\
Predictor & Regime & edf & p-value \\
\hline SSB & - & $1.37(1.45)$ & $<0.001(<0.001)$ \\
SST & SSB $\leq \Phi$ & $1.00(1.00)$ & $<0.001(<0.001)$ \\
[Oxygen] & SSB $\leq \Phi$ & $1.00(1.00)$ & $<0.001(0.003)$ \\
\hline
\end{tabular}

range of model uncertainty, i.e. within the prediction intervals. Also, the hindcasted recruitment simulations (based on only initial numbers-at-age in 1971) reasonably recreate the historical recruitment levels throughout the period but overestimate mean recruitment levels, especially during more recent years (Fig. 2F). Model residuals were normally distributed and temporally uncorrelated (Fig. 3). Furthermore, the TGAM formulation proved significantly better than a regular GAM, as indicated by a lower genuine CV (i.e. 0.54 compared to 0.59) and higher deviance explained (i.e. $84.3 \%$ compared to $69.7 \%$ ).

The forecasted cod stock dynamics under different climate and mortality scenarios (i.e. by varying climate conditions over the range of their historical distribution and varying $Z$ between 0.2 to 1.2 ) illustrate a low probability of stock recovery, above the estimated threshold of $7193 \mathrm{t}$, with increasing total mortality rates and unfavourable climate conditions (i.e. high SST and low oxygen concentrations) (Fig. 4A,B). Regarding recovery above $B_{\mathrm{pa}}=10500 \mathrm{t}$, even lower probabilities are evident with increasing total mortality rates and unfavourable climate conditions (Fig. 4C,D). In cases where climate conditions remain at unfavourable levels, maintaining the present total mortality rates $(Z=1)$ throughout the $10 \mathrm{yr}$ simulation results in a very low probability of stock recovery above the threshold or $B_{\mathrm{pa}}$. The simulations using mortalities from the 2 ICES assessment runs both indicate that only by drastically reducing $\mathrm{Z}$ to $\leq 0.3$ may the stock recover above the critical threshold level at the current climatic conditions.

\section{DISCUSSION}

Many of the Atlantic cod stocks have declined dramatically in recent decades and still remain at histor- 

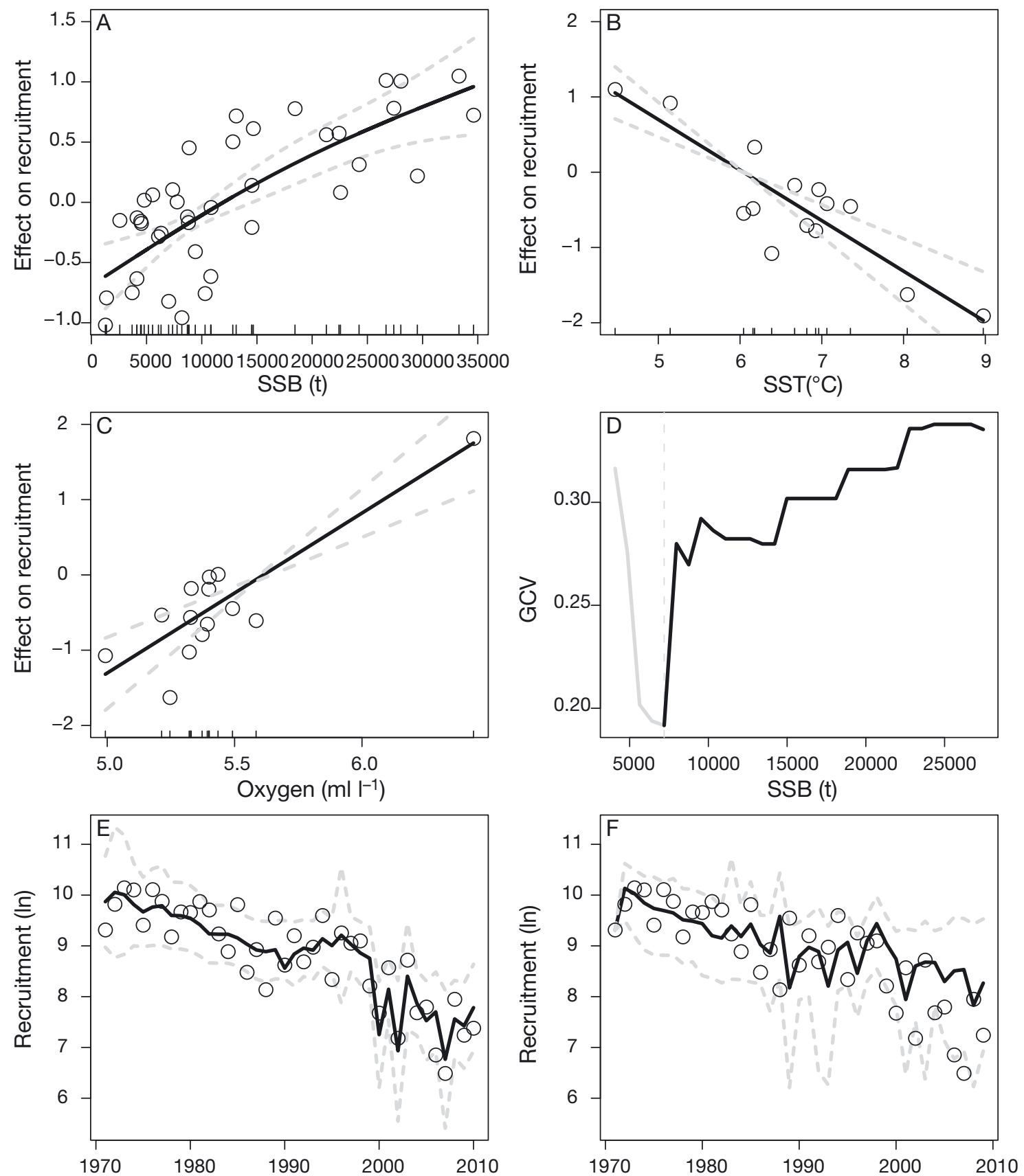

Fig. 2. Final smooth terms with $95 \%$ confidence intervals (dashed lines) illustrating the relationships between recruitment and (A) spawning stock biomass (SSB), (B) spring sea surface temperature (SST) and (C) winter bottom oxygen as well as (D) the estimated SSB threshold (vertical line) below which the climate effects proved significant. (E) Predicted and (F) hindcasted recruitment with $95 \%$ prediction intervals (dashed lines) based on an age-structured model initialised with observed numbers-at-age (in 1971) and forced with observed climate and estimated F-at-age (fishing mortality) throughout the period. Observed values are shown as circles. Note that predicted values and residuals are adjusted to an average value of zero and are therefore not directly comparable

ically low levels (Hutchings \& Reynolds 2004, Lilly et al. 2008). These collapses are largely considered to have resulted from overfishing (Cook et al. 1997, Myers et al. 1997); however, climate-driven declines in productivity have in several cases also been de- monstrated (Beaugrand et al. 2003, Stige et al. 2006). At the same time, some stocks have partially recovered, for example the eastern Baltic cod, for which improved recruitment production played a central role in recovery (Eero et al. 2012). The climate effect 

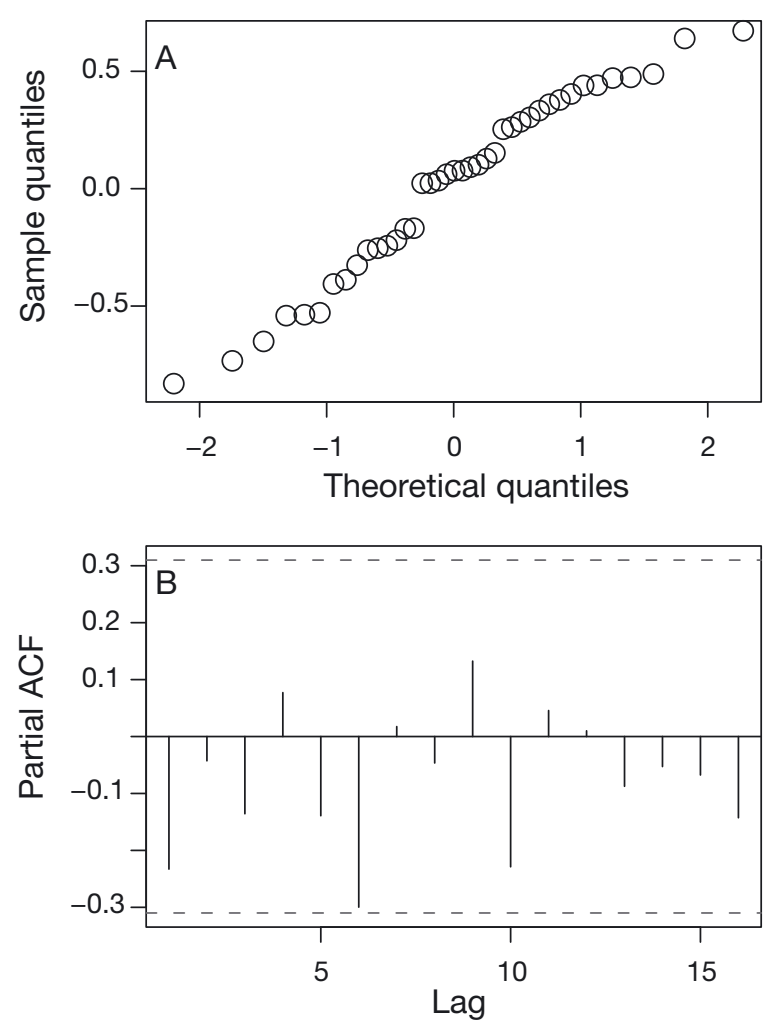

Fig. 3. (A) Normal probability plot and (B) partial autocorrelation function (ACF) plot of the final stock-recruitment model for the Kattegat cod

generally works through changes in the physical environment (e.g. temperature and salinity) but also through altered food supply for early life-history stages, eventually affecting recruitment (Ottersen et al. 2001, Beaugrand et al. 2003, Stige et al. 2006). Our results suggest that in addition to the effects of overexploitation, which has hitherto been considered the main factor responsible for the decline of this population, climatic factors may influence recruitment and the potential for recovery of the Kattegat cod. Furthermore, our findings support the theory that climate influences recruitment and stock productivity primarily during periods of low stock size (Brander 2005) caused, for example by overfishing and fisheryinduced demographic changes (Ottersen et al. 2006, Anderson et al. 2008).

Climate conditions in the Kattegat and Baltic Sea are mainly influenced by large-scale circulation patterns causing changes in temperature regimes throughout the area, as well as periodic inflows of high salinity and oxygen-rich water from the North Sea (Matthäus \& Franck 1992, Danielsson et al. 2004). The influence of such large-scale regional climate forcing on cod recruitment is supported by previous studies on the effects of NAO on cod stocks throughout the North Atlantic (Ottersen et al. 2001, Brander \& Mohn 2004), whose recruitment is generally positively affected in the western and northern parts but negatively impacted in the eastern and southern parts of the area (Stige et al. 2006). The reason for the opposite effects of the NAO is explained by the different effect of temperature across the area (Mantzouni et al. 2010): cod stocks in the northern limit of their distribution (thermal) range are positively affected by increasing temperature (e.g. in the Barents Sea), while further temperature increases in the southern and warmer areas (e.g. Baltic Sea) may negatively affect recruitment (Planque \& Fredou 1999). Our results are consistent with these findings and suggest that increasing temperatures and/or indirect processes (e.g. those channelled through lower trophic levels; Beaugrand et al. 2003) acting on growth and survival of early life stages may have impaired Kattegat cod recruitment, especially during periods of low stock size. Furthermore, frequent periods of widespread hypoxia and anoxia may cause high mortalities for benthic organisms as well as for juvenile and adult fish in the Kattegat (Pihl 1994, Kruse \& Rasmussen 1995, Karlson et al. 2002). In the Central Baltic Sea, low oxygen conditions in the deep basins have been shown to limit recruitment of Eastern Baltic cod through increased egg and larvae mortality (Köster et al. 2005). However, direct mortality during the pelagic egg and larval stages seems less likely in the Kattegat, due to the higher salinity and lower risk of egg and larvae being exposed to hypoxia/anoxia. Therefore, reduced juvenile survival (once settled at the bottom), caused by direct mortality and/or indirect effects through reduced food availability and changes in benthic community composition (Pihl 1994, Karlson et al. 2002), especially in the shallow nursery areas highly affected by coastal eutrophication and seasonal hypoxia/anoxia, seems a more plausible mechanism for the suggested effect of oxygen on cod recruitment in the Kattegat. Furthermore, since anoxia in the Kattegat may occur over short temporal scales, i.e. as anoxic/ hypoxic water masses may suddenly be upwelled into more shallow nursery areas, neither mobile (fish) nor sessile (benthos) organisms may evade such habitats, resulting in massive mortality events ('fish kills') (Kruse \& Rasmussen 1995).

Overfishing reduces the mean age, mean size and geographic diversity of populations and therefore increases the sensitivity of fish stocks to climatedriven recruitment stress (Ottersen et al. 2006, Anderson et al. 2008). This may further impair their resilience to withstand and buffer against environ- 

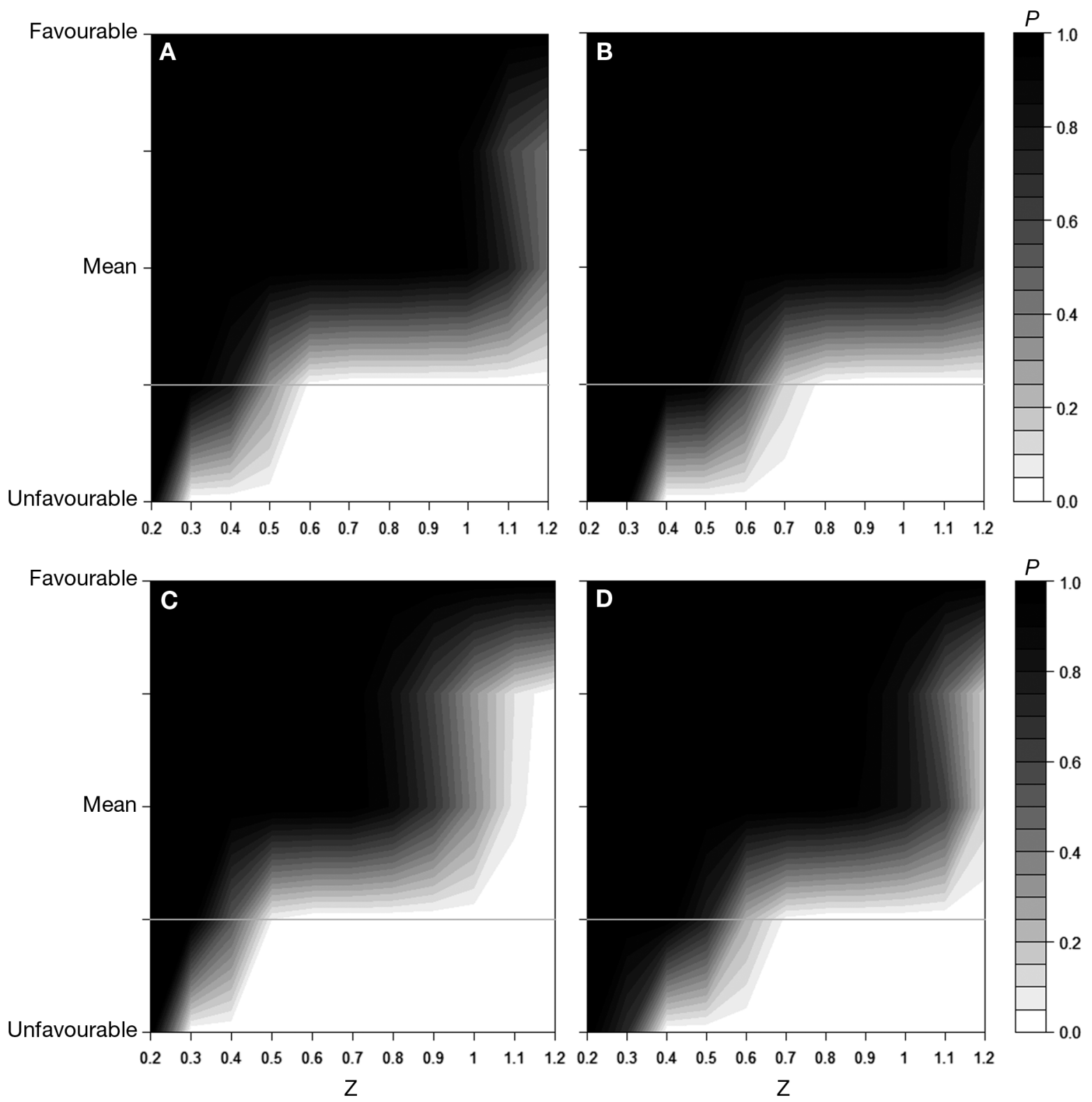

Fig. 4. Probability $(P)$ of cod stock recovery, defined as the percentage of simulations in which the SSB increased above $(\mathrm{A}, \mathrm{B})$ the estimated threshold level of $7193 \mathrm{t}$ or $(\mathrm{C}, \mathrm{D})$ the precautionary stock size $\left(B_{\mathrm{pa}}=10500 \mathrm{t}\right)$. The simulations were performed over a 10 yr period given a combination of total mortalities (Z) and climate, ranging from unfavourable to favourable conditions for recruitment (i.e. maximum SST and minimum oxygen concentrations and vice versa). (Present climate conditions are indicated by horizontal lines.) The Z-at-age values are based on $(\mathrm{A}, \mathrm{C})$ assessment runs excluding discards but estimating total removals within the model as well as $(\mathrm{B}, \mathrm{D})$ runs including discards

mental change (Lindegren et al. 2010). The demographic condition (i.e. age and size distribution) of the Kattegat cod is poor (Svedäng et al. 2002), and several important sub-stocks have been depleted due to intensive trawl fishing (Svedäng et al. 2010). Decrease in the numbers of large, old and experienced spawners directly reduces the number of generations contributing to spawning and likely also shortens the duration of the spawning period (Wright
\& Trippel 2009). Consequently, the Kattegat cod, presently at very low biomass, is likely less resilient to various stress factors, e.g. periods of unfavourable abiotic conditions.

Our results indicate that the long-term decrease and the present poor state of the Kattegat cod stock is likely due to high total mortality rates, which may not only have caused a decrease in stock size but are also currently preventing recovery due to threshold- 
dependent climate effects on recruitment. Fishing for cod has been markedly reduced in recent years, as illustrated by very low catch ratios (Fig. 1B). However, discards of juvenile cod in economically valuable Nephrops fisheries continue to be a problem (ICES 2012). Although recent changes in management measures (e.g. gear selectivity, closed areas and reduction in effort) have resulted in significant reduction in fishing impact on Kattegat cod (Vinther \& Eero 2013), the current level of fishery-induced mortality may still be too high to promote a future recovery of the stock in the present climate. SST and oxygen concentrations in the Kattegat are projected to increase and decrease by $\sim 2^{\circ} \mathrm{C}$ and $0.6 \mathrm{ml}^{-1}$, respectively, during the 21st century (Meier et al. 2012). The findings of the present study suggest that under this climate scenario, reducing total mortality levels to $\leq 0.3$ would be needed to allow the cod stock to recover above the estimated threshold level or above the $B_{\mathrm{pa}}$ (Fig. 4). Lessons learned from the Eastern Baltic cod stock show that recovery is indeed possible, given the correspondence between landing quotas and fishery removals from the stock (Eero et al. 2012). The role of biological or other uncontrollable factors in the current total mortality of Kattegat cod estimated in ICES is unclear, which complicates the achievement of certain mortality values for this stock by management measures (Kraak et al. 2012). Nevertheless, our results indicate that with the present climate conditions and stock size, the stock could withstand almost no or only minimal fishing pressure in order to be able to recover. To that end, the recommended target fishing mortality of 0.4 may under current conditions prove unsustainable (EC 2008).

The incorporation of hydrographic and ecosystem considerations can improve recruitment predictions and consequently the estimates of future potential stock development. Furthermore, the case of the Kattegat cod demonstrates the importance of understanding threshold-dependent ecological processes that influence the dynamics of fish populations when developing sustainable ecosystem-based fisheries management practices worldwide.

Acknowledgements. We thank colleagues at NERI, SMHI and ICES for maintaining long-term monitoring and publicly accessible data bases. This research was funded by the Danish Council for Strategic Research and is a contribution to the project 'IMAGE'.

\section{LITERATURE CITED}

Anderson CNK, Hsieh CH, Sandin SA, Hewitt R and others (2008) Why fishing magnifies fluctuations in fish abun- dance. Nature 452:835-839

Andersson L (1996) Trends in nutrient and oxygen concentrations in the Skagerrak-Kattegat. J Sea Res 35:63-71

- Beaugrand G, Brander KM, Lindley JA, Souissi S, Reid PC (2003) Plankton effect on cod recruitment in the North Sea. Nature 426:661-664

> Brander KM (2005) Cod recruitment is strongly affected by climate when stock biomass is low. ICES J Mar Sci 62: 339-343

> Brander K, Mohn R (2004) Effect of the North Atlantic Oscillation on recruitment of Atlantic cod (Gadus morhua). Can J Fish Aquat Sci 61:1558-1564

Caddy JF, Agnew DJ (2004) An overview of recent global experience with recovery plans for depleted marine resources and suggested guidelines for recovery planning. Rev Fish Biol Fish 14:43-112

> Cardinale M, Svedäng H (2004) Modelling recruitment and abundance of Atlantic cod, Gadus morhua, in the eastern Skagerrak-Kattegat (North Sea): evidence of severe depletion due to a prolonged period of high fishing pressure. Fish Res 69:263-282

> Ciannelli L, Chan K, Bailey K, Stenseth N (2004) Nonadditive effects of the environment on the survival of a large marine fish population. Ecology 85:3418-3427

Conley DJ, Carstensen J, Aertebjerg G, Christensen PB, Dalsgaard T, Hansen JLS, Josefson AB (2007) Long-term changes and impacts of hypoxia in Danish coastal waters. Ecol Appl 17:S165-S184

Cook RM, Sinclair A, Stefansson G (1997) Potential collapse of North Sea cod stocks. Nature 385:521-522

Courchamp F, Berec L, Gascoigne J (2009) Allee effects in ecology and conservation. Oxford University Press, Oxford

Danielsson A, Rahm L, Conley DJ, Carstensen J (2004) Identification of characteristic regions and representative stations: a study of water quality variables in the Kattegat. Environ Monit Assess 90:203-224

- Eero M, Koster F, Vinther M (2012) Why is the Eastern Baltic cod recovering? Mar Policy 36:235-240

European Commission (EC) (2008) Council Regulation No. 1342/2008 of 18 December 2008 establishing a long-term plan for cod stocks and the fisheries exploiting those stocks and repealing Regulation (EC) No. 423/2004. EC, Brussels

> Frank KT, Petrie B, Choi JS, Leggett WC (2005) Trophic cascades in a formerly cod-dominated ecosystem. Science 308:1621-1623

> Gustafsson B (2000) Time-dependent modeling of the Baltic entrance area. 1. Quantification of circulation and residence times in the Kattegat and the straits of the Baltic sill. Estuaries 23:231-252

- Hammer C, von Dorrien C, Hopkins CCE, Köster FW, Nilssen EM, St John M, Wilson DC (2010) Framework of stock-recovery strategies: analyses of factors affecting success and failure. ICES J Mar Sci 67:1849-1855

> Henriksen P (2009) Long-term changes in phytoplankton in the Kattegat, the Belt Sea, the Sound and the western Baltic Sea. J Sea Res 61:114-123

Hilborn R, Litzinger E (2009) Causes of decline and potential for recovery of Atlantic cod populations. The Open Fish Sci J 2:32-38

> Hutchings JA, Reynolds JD (2004) Marine fish population collapses: consequences for recovery and extinction risk. Bioscience 54:297-309

Hutchings JA, Minto C, Ricard D, Baum JK, Jensen OP 
(2010) Trends in the abundance of marine fishes. Can J Fish Aquat Sci 67:1205-1210

ICES (2012) Report of the Baltic Fisheries Assessment Working Group (WGBFAS), 12-19 April 2012. ICES Headquarters, Copenhagen ICES CM 2012/ACOM:10

Karlson K, Rosenberg R, Bonsdorff E (2002) Temporal and spatial large-scale effects of eutrophication and oxygen deficiency on benthic fauna in Scandinavian and Baltic waters-a review. Oceanogra Mar Biol Annu Rev 40: 427-489

Keith DM, Hutchings JA (2012) Population dynamics of marine fishes at low abundance. Can J Fish Aquat Sci 69: 1150-1163

Köster FW, Möllmann C, Hinrichsen HH, Wieland $\mathrm{K}$ and others (2005) Baltic cod recruitment - the impact of climate variability on key processes. ICES J Mar Sci 62: 1408-1425

Kraak SBM, Bailey N, Cardinale M, Darby C and others (2012) Lessons for fisheries management from the EU cod recovery plan. Marine Policy 37:200-213

Kruse B, Rasmussen B (1995) Occurrence and effects of a spring oxygen minimum layer in a stratified coastal water. Mar Ecol Prog Ser 125:293-303

Lilly GR, Wieland K, Rothschild BJ, Sundby S and others (2008) Decline and recovery of Atlantic cod (Gadus morhua) stocks throughout the North Atlantic. In: Kruse GH, Drinkwater K, Ianelli JN, Link JS, Stram DL, Wespestad V, Woodby D (eds) Resiliency of gadid stocks to fishing and climate change. Alaska Sea Grant Program, University of Alaska Fairbanks, p 39-66

Lindegren M, Möllmann C, Nielsen A, Stenseth NC (2009) Preventing the collapse of the Baltic cod stock through an ecosystem-based management approach. Proc Natl Acad Sci USA 106:14722-14727

Lindegren M, Diekmann R, Möllmann C (2010) Regime shifts, resilience and recovery of a cod stock. Mar Ecol Prog Ser 402:239-253

Lindegren M, Blenckner T, Stenseth NC (2012) Nutrient reduction and climate change cause a potential shift from pelagic to benthic pathways in a eutrophic marine ecosystem. Glob Change Biol 18:3491-3503

Lindegren $M$, Waldo S, Nilsson A, Svedäng $H$, Persson A (2013) Towards sustainable fisheries of the Öresund cod (Gadus morhua) through sub-stock specific assessments and management recommendations. ICES J Mar Sci, doi: 10.1093/icesjms/fst042

Llope M, Daskalov GM, Rouyer TA, Mihneva V, Chan K, Grishin AN, Stenseth NC (2011) Overfishing of top predators eroded the resilience of the Black Sea system regardless of the climate and anthropogenic conditions. Glob Change Biol 17:1251-1265

> Mantzouni I, Sørensen H, O'Hara RB, MacKenzie BR (2010) Hierarchical modelling of temperature and habitat size effects on population dynamics of North Atlantic cod. ICES J Mar Sci 67:833-855

> Margonski P, Hansson S, Tomczak MT, Grzebielec R (2010) Climate influence on Baltic cod, sprat, and herring stockrecruitment relationships. Prog Oceanogr 87:277-288

Matthäus W, Franck H (1992) Characteristics of major Baltic inflows - a statistical analysis. Cont Shelf Res 12: $1375-1400$

McLeod K, Leslie H (2009) Ecosystem-based management for the oceans. Island Press, Washington, DC

$>$ Meier HEM, Hordoir R, Andersson HC, Dieterich $\mathrm{C}$ and

Editorial responsibility: Konstantinos Stergiou,

Thessaloniki, Greece others (2012) Modeling the combined impact of changing climate and changing nutrient loads on the Baltic Sea environment in an ensemble of transient simulations for 1961-2099. Clim Dyn 39:2421-2441

- Myers RA, Hutchings JA, Barrowman NJ (1997) Why do fish stocks collapse? The example of cod in Atlantic Canada. Ecol Appl 7:91-106

> Ottersen G, Planque B, Belgrano A, Post E, Reid PC, Stenseth NC (2001) Ecological effects of the North Atlantic Oscillation. Oecologia 128:1-14

Ottersen G, Hjermann DO, Stenseth NC (2006) Changes in spawning stock structure strengthen the link between climate and recruitment in a heavily fished cod (Gadus morhua) stock. Fish Oceanogr 15:230-243

> Pedersen FB (1993) Fronts in the Kattegat: the hydrodynamic regulating factor for biology. Estuaries 16: 104-112

Pihl L (1994) Changes in the diet of demersal fish due to eutrophication-induced hypoxia in the Kattegat, Sweden. Can J Fish Aquat Sci 51:321-336

Planque B, Fredou T (1999) Temperature and the recruitment of Atlantic cod (Gadus morhua). Can J Fish Aquat Sci 56:2069-2077

Rydberg L, Aertebjerg G, Edler L (2006) Fifty years of primary production measurements in the Baltic entrance region, trends and variability in relation to land-based input of nutrients. J Sea Res 56:1-16

> Shelton PA, Sinclair AF, Chouinard GA, Mohn R, Duplisea DE (2006) Fishing under low productivity conditions is further delaying recovery of Northwest Atlantic cod (Gadus morhua). Can J Fish Aquat Sci 63:235-238

Stige LC, Ottersen G, Brander K, Chan KS, Stenseth NC (2006) Cod and climate: effect of the North Atlantic Oscillation on recruitment in the North Atlantic. Mar Ecol Prog Ser 325:227-241

Svedäng H, Øresland V, Cardinale M, Hallbäck H, Jakobsson P (2002) De kustnära fiskbeståndens utveckling och nuvarande status vid svenska västkusten. Synopsis av 'Torskprojektet steg I-III'. Fiskeriverket informerar (Finfo) 2002:6

> Svedäng H, Stål J, Sterner T, Cardinale M (2010) Consequences of subpopulation structure on fisheries management: cod (Gadus morhua) in the Kattegat and Öresund (North Sea). Rev Fish Sci 18:139-150

Vinther M, Eero M (2013) Quantifying relative fishing impact on fish populations based on spatio-temporal overlap of fishing effort and stock density. ICES J Mar Sci 70:618-627

Vitale F, Cardinale M, Svedäng H (2005) Evaluation of the temporal development of the ovaries in Gadus morhua from the Sound and Kattegat, North Sea. J Fish Biol 67 : 669-683

> Wakeford RC, Agnew DJ, Mees CC (2009) Review of institutional arrangements and evaluation of factors associated with successful stock recovery plans. Rev Fish Sci 17: 190-222

Wood SN (2003) Thin plate regression splines. J R Stat Soc B 65:95-114

Wood SN (2004) Stable and efficient multiple smoothing parameter estimation for generalized additive models. J Am Stat Assoc 99:673-686

Wright P, Trippel EA (2009) Fishery-induced demographic changes in the timing of spawning: consequences for reproductive success. Fish Fish 10:283-304

Submitted: February 15, 2013; Accepted: June 6, 2013

Proofs received from author(s): August 14, 2013 